\title{
REACTION OF THE MOUSE UTERUS DURING IMPLANTATION AND DECIDUOMA FORMATION AS DEMONSTRATED BY CHANGES IN THE DISTRIBUTION OF ALKALINE PHOSPHATASE
}

\author{
C. A. FINN ANd J. R. HINCHLIFFE \\ Department of Biological Sciences, \\ Wye College (University of London), Ashford, Kent
}

(Received 6th April 1964)

Summary. (I) Using a histochemical technique, alkaline phosphatase has been shown to appear in the stroma of the mouse uterus during implantation and after initiation of the oil-induced deciduoma.

(2) In sections of pregnant uteri the enzyme first appeared on the 5th day after mating as a small crescentic area in the stroma on the antimesometrial side of the uterus close to the implanting blastocyst.

(3) In pseudopregnant mice after instillation of oil into the uterine lumen (on the 4th day) a similar crescentic area of alkaline phosphatase activity appeared around the uterine lumen on the antimesometrial side on the 5 th day.

(4) The epithelium in both cases is intact on the 5th day but degeneration occurs on the antimesometrial side on the 6 th day. This suggests that epithelial degeneration is an inherent property of the uterus during the period of implantation, and is not directly caused by the activities of the giant cells of the trophoblast.

(5) There was no alkaline phosphatase activity in the uterine stroma of pseudopregnant untreated mice on the 4 th, 5 th and 6 th days after sterile mating and the epithelium showed no evidence of degeneration. Further, injection of oil into the uteri of ovariectomized mice failed to cause epithelial degeneration or result in alkaline phosphatase activity in the stroma.

(6) The bearing of these results on the role of the blastocyst in implantation is discussed.

\section{INTRODUCTION}

Following Loeb's (1908) discovery that the uterus of a pseudopregnant guineapig could be stimulated to undergo decidualization by traumatization of the endometrium, much work has been directed to seeking a chemical substance which might provide the decidual stimulus during implantation or following trauma. The effectiveness of trauma as a decidual stimulus has led to the belief that the blastocyst also acts by traumatizing the epithelial lining of the uterus. This view has been held in spite of the fact that decidual cell formation starts while the 
blastocyst is making only very light contact with the wall of the uterus and the epithelial lining shows no visible sign of damage. It has led Shelesnyak (1959) and his colleagues to suggest that histamine is the final stimulus for the decidual cell reaction. Recently, however, the histamine hypothesis has been challenged by several workers (Finn \& Keen, 1962; De Feo, 1962; Orsini, 1963; Wrenn, Bitman, Cecil \& Gilliam, 1964) who have been unable to repeat some of the crucial experiments in support of it.

The injection of small quantities of solution into the uterus of pseudopregnant rats or mice, provides a simple and effective method of testing the effectiveness of a compound as a decidual stimulus. Using this technique, Finn \& Keen (1963) showed that, of many substances tested, only oils and certain sulphated polysaccharides stimulated a decidual response significantly greater than could be accounted for by the trauma of injection. They suggested on this and other evidence that there might be some association between sulphated polysaccharides and the implantation of the blastocyst.

In view of the frequent association of the enzyme alkaline phosphatase with mucopolysaccharides in tissues (Moog \& Wenger, 1952) and the known presence of the enzyme in pregnant rat uteri (Pritchard, 1947) it was decided to investigate the distribution of the enzyme in the uterus at the time of implantation and during the initiation of the decidual cell reaction by oil.

\section{METHODS}

Mice of the C.F.1. strain randomly bred in the college animal house were used. Pregnancy or pseudopregnancy was induced by placing the females overnight with intact or vasectomized males. The day a copulation plug was found in the vagina was taken to be Day 1 or the first day of pregnancy or pseudopregnancy. Oil was injected through the uterotubal junction (which was exposed through a small incision in the flank) on Day 4 of pseudopregnancy. In preliminary trials it was found that $0.03 \mathrm{ml}$ arachis oil injected into the left horn of the uterus on the afternoon of Day 4 stimulated good deciduoma formation in both horns of the uterus. (In the mouse, unlike the rat, oil can pass from one horn to the other.) This regime was therefore used throughout the experiment. The mice were killed by dislocation of the neck and the uterus was removed and placed in fixative.

Alkaline phosphatase was demonstrated by a modification of the Gomori (1952) calcium-cobalt method. Various fixatives were tried, the most satisfactory of which was found to be $80 \%$ alcohol. Pieces of uterus were left in this overnight at $4^{\circ} \mathrm{C}$. After a minimum time dehydrating and clearing (in benzene), the blocks were embedded for 20 min under pressure in three changes of wax of low melting point $\left(45^{\circ} \mathrm{C}\right)$, thus minimizing enzyme destruction. Sections were cut at $10 \mu$ and incubated for $2 \mathrm{hr}$ in the Gomori glycerophosphate medium, the calcium phosphate formed being made visible by conversion to cobalt sulphide in the usual way. In preliminary trials, $2 \mathrm{hr}$ was found to be the optimum incubation time. As a control, some slides were heated to $100^{\circ} \mathrm{C}$ for a few hours before incubation. In all cases these were negative for the enzyme. The slides were mounted in glycerine jelly as most other mountants were found to dissolve the cobalt sulphide deposit. 
Although this method is not quantitative, it gives a good assessment of the distribution of the enzyme and notwithstanding its simplicity provides a very adequate picture of changes in the distribution.

The numbers of mice examined in each group are shown in Table 1.

The groups containing mice undergoing a decidual response, that is the 5- and 6-Day pregnant and 5- and 6-Day oil-injected pseudopregnant groups, showed some variation in the progress of the response. This is, of course, to be expected in an active biological reaction. In these groups, therefore, it was necessary to examine fairly large numbers of animals in order to be certain of the average response on each day. In the text we have given some indication of the extent to which variation occurred, although it was not found possible to measure it strictly. The other groups, in which a decidual response did not occur, showed little variation, so that it was not necessary to examine large numbers of uteri.

TABLE 1

NUMBERS OF MICE IN EACH EXPERIMENTAL GROUP

\begin{tabular}{l|r|r|r|r}
\hline & \multicolumn{3}{|c|}{ Day } & \\
\cline { 2 - 4 } & 4 & 5 & 6 & Total \\
\hline Pregnant & 6 & 16 & 17 & 39 \\
Oil induced deciduoma & 5 & 19 & 23 & 47 \\
Pseudopregnant & 4 & 4 & 4 & 12 \\
Ovariectomized & & & & 4 \\
Ovariectomized +oil & & & & 6 \\
\hline
\end{tabular}

\section{OBSERVATIONS}

All the sections of uteri examined showed a strongly positive area of alkaline phosphatase activity just below the serosa (Plates 1, 2 and 3 ). As this did not vary during any of the physiological states being studied, it is of no significance in the present context. The distribution of the enzyme in the epithelium and stroma, however, changed during implantation and deciduoma formation as described below.

\section{PREGNANT ANIMALS}

Day 4. On the 4th day the blastocyst does not appear to have made contact with the endometrium. The luminal surface of the epithelium is strongly positive for alkaline phosphatase but the stroma is negative. There are many glands in the stroma which have a positive area round their basement membrane and sometimes positive material in the lumen (Pl. 1, Figs. 2 and 4).

Day 5. Uteri were taken from pregnant mice on the morning or afternoon of Day 5. As it is not possible to see the position of the implanting blastocyst macroscopically at this time, a fairly long portion of a uterine horn was taken and serially sectioned. In most cases one or more blastocysts were found.

In all sections from areas between implanting blastocysts, very little alkaline phosphatase was present. Sections from parts of the uterus containing a blastocyst contained alkaline phosphatase in the stroma. The lumen of the uterus is elongated at this time in a mesometrial-antimesometrial direction and the positively 
stained area starts as a crescent round the antimesometrial border of the lumen where the blastocyst is making contact with the endometrium. The epithelial cells at this time are intact, columnar and clear of alkaline phosphatase ( $\mathrm{Pl} .2$, Figs. 6 and 8). The only apparent difference between the uteri of mice killed in the morning or afternoon was in the size and extent of the area of positive staining in the stroma.

Day 6. Sections from uteri taken on the 6th day again showed little alkaline phosphatase in areas of the uterus not containing a blastocyst. In fact sections from these areas on Days 5 and 6 were similar to those from pseudopregnant uteri (see below). Where a blastocyst was present in the lumen, the stroma was intensely stained for alkaline phosphatase, which was found throughout most of the stroma by the morning of Day 6 . The epithelium around the blastocyst was partially or completely destroyed at this time. A noticeable feature on the 6th day was a small area free of alkaline phosphatase at the base of the implantation crypt (Pl. 3, Figs. 10 and 12).

PSEUDOPREGNANT ANIMALS AFTER INJECTION OF OIL INTO THE UTERUS

Day 4. The mice were killed $6 \mathrm{hr}$ after the instillation of oil. Sections of uteri showed intense staining of the free surface of the epithelium but no positive area in the stroma (Pl. 1, Figs. 1 and 3).

Day 5. On the morning of Day 5, most uteri showed a small crescentic area of enzyme activity around the epithelium on the antimesometrial side. As in the pregnant animals the lumen is orientated in a mesometrial-antimesometrial direction. By the afternoon the positive area was more extensive but was still only surrounding the antimesometrial border of the lumen. In all the morning sections and most of the afternoon ones, the epithelium was intact and clear of alkaline phosphatase (Pl. 2, Figs. 5 and 7). Sections of uteri from mice killed on the afternoon of Day 5 occasionally showed epithelial changes characteristic of Day 6.

Day 6. Uteri from mice killed on the morning of Day 6 showed a very pronounced difference in the epithelium between the mesometrial and antimesometrial boundaries of the lumen. As in the pregnant animals the epithelium on the mesometrial border was intact, and cuboidal or columnar. However, on the antimesometrial border the epithelium appeared to be breaking down. The cells were small and contained very little cytoplasm. They appeared as beadlike strands detached from the underlying stroma, thus causing a break in the endometrial lining similar to an implantation crypt. The strands of broken-down epithelial cells were alkaline-phosphatase-positive whereas the intact cells on the mesometrial border were clear of the enzyme (Pl. 3, Fig. 11). There was usually an alkaline-phosphatase-free area of stroma at the base of the crypt also. In following serial sections along the length of the uterus, it was noticeable that the depth of the crypt varied considerably and it seems possible that the crypts represent foci of decidual development. It is worth noting here that, when one examines oil deciduomata macroscopically on the seventh day, one often finds many discrete swellings along the length of the uterus which are probably correlated with these foci. Almost all the stromal tissue at this time gave a positive reaction for phosphatase. 
PI.ATE I

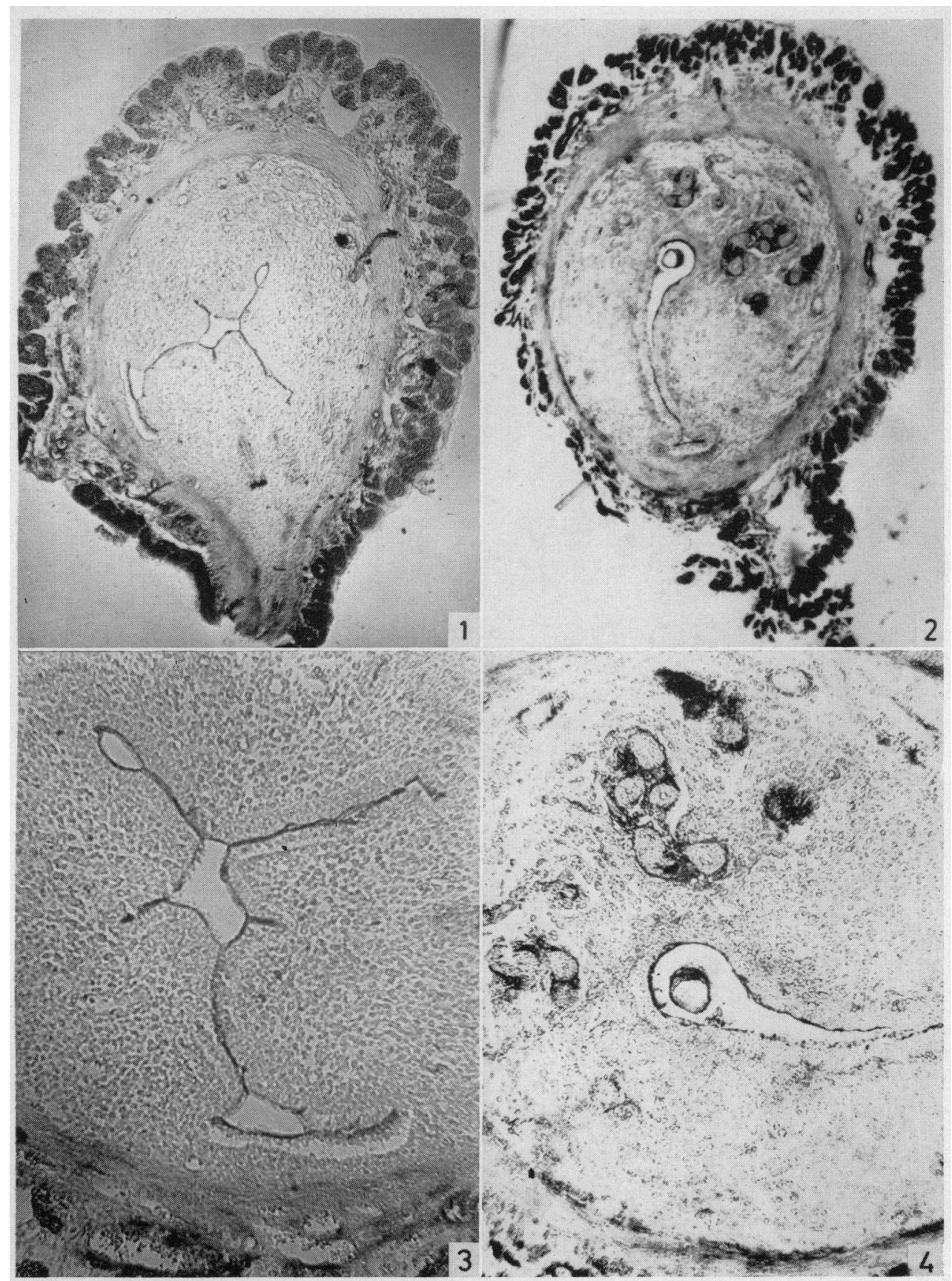

Figs. 1 and 3. T.S. of uterus on 4th day of pseudopregnancy, $6 \mathrm{hr}$ after instillation of oil.

Fig. $1 \times 90$, Fig. $3 \times 260$.

Figs. 2 and 4 . T.S. of uterus on 4 th day of pregnancy, showing blastocyst in lumen.

Fig. $2 \times 100$, Fig. $4 \times 210$. 


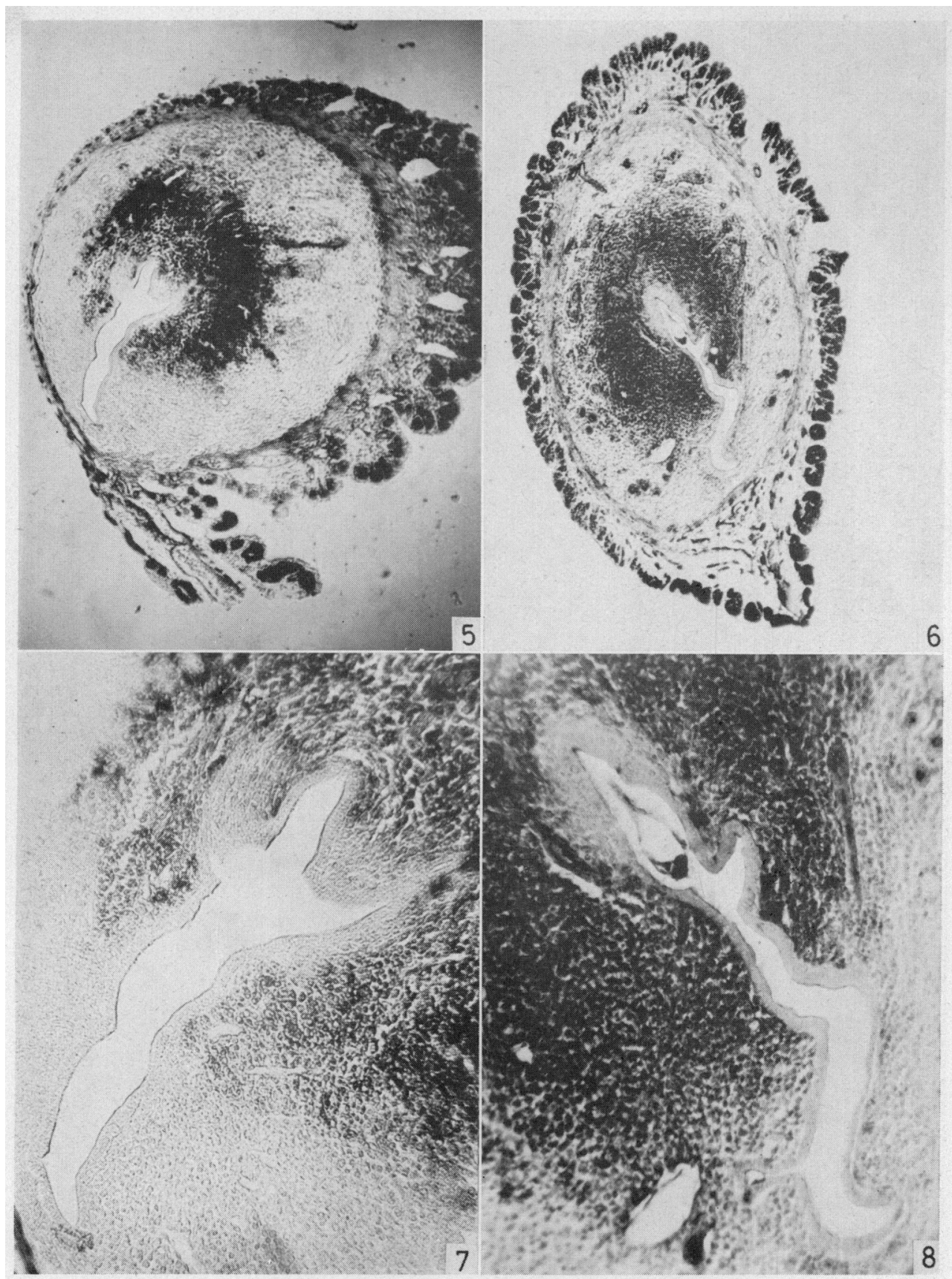

FIGs. 5 and 7. T.S. of uterus on 5 th day of pseudopregnancy after instillation of oil on afternoon of 4 th day. Fig. $5 \times 70$, Fig. $7 \times 220$.

Figs. 6 and 8 . T.S. of uterus on 5 th day of pregnancy, showing blastocyst in lumen. Fig. $6 \times 70$, Fig. $8 \times 220$. 


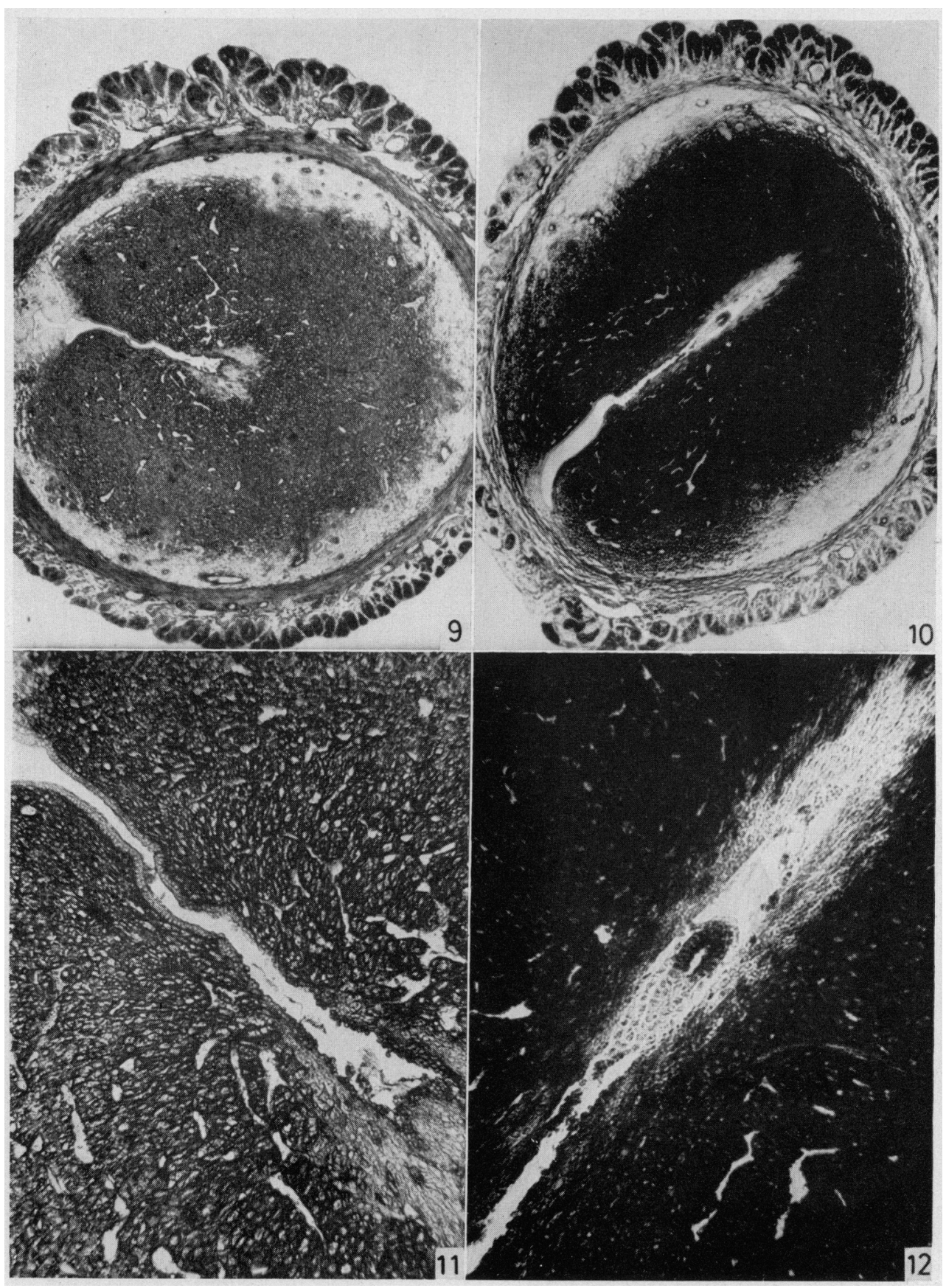

Fiss. 9 and 11. T'S. oluterus on bih day of pseudopregnaney after instillation of oil on

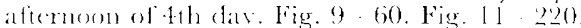

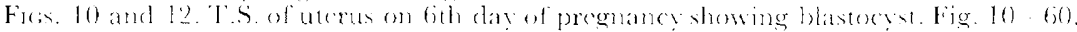
Fig. 1'2 180 . 
Sections of uteri taken from pseudopregnant untreated mice on Days 4, 5 and 6 were examined for alkaline phosphatase.

On Day 4, the picture was similar to that found on the 4th day in pregnant mice or in pseudopregnant mice after the injection of oil. On Days 5 and 6, however, no alkaline phosphatase appeared in the stroma and the epithelium remained intact and lost the positive staining. Thus in the absence of deciduainducing stimulus the stroma, although under the necessary hormone control, remained free of alkaline phosphatase.

OVARIECTOMIZED ANIMALS AFTER INJECTION OF OIL INTO THE UTERUS

The uteri of ovariectomized mice injected with arachis oil were examined for alkaline phosphatase 24 and $48 \mathrm{hr}$ after injection and compared with control ovariectomized animals. The times correspond, in terms of the length of time since the instillation of the oil, with Days 5 and 6 in the oil-deciduoma groups. Both the control and the treated ovariectomized mice showed strong positive staining of the luminal surface of the epithelium with no enzyme activity in the stroma on either day. The epithelium was intact and appeared normal in the oil-injected group. Thus it appears that the oil stimulus in itself does not cause destruction of the epithelium or appearance of alkaline phosphatase in the stroma.

\section{DISCUSSION}

The appearance of alkaline phosphatase in the stroma of the pregnant uterus appears to be associated, at least temporally, with the induction of the decidual cell reaction. It is interesting that it appears before the actual nidation of the ovum into the wall of the uterus and before there is any observable change in the epithelium. The finding that the stromal reaction occurs before degeneration of the epithelium is in contrast with the statement by Amoroso (1952) that "with the destruction of the epithelium appears the first sign of decidual formation".

There is still much confusion over the functional significance of alkaline phosphatase, which has been linked with several different physiological processes, e.g. with the turnover of DNA within the nucleus, with secretion, and with the formation of fibrous proteins (see Danielli, 1953). Probably most relevant to its presence in the decidual cells is Moog's (1944) finding that in the chick, most tissues during differentiation show waves of alkaline phosphatase activity. Thus the presence of the enzyme in stromal cells, which are beginning to divide actively, may be linked with its presence in differentiating tissues in general.

The enzyme is also found in the stroma of the pseudopregnant uterus after the instillation of arachis oil, a potent stimulus for the decidual cell reaction. This observation adds histochemical evidence to the previous morphological evidence that the artificially induced deciduoma reaction of the uterus closely parallels the decidual cell reaction of pregnancy. From the distribution of the enzyme several interesting facts about the reaction in response to oil have emerged.

The earliest reaction of the stroma in the oil-injected pseudopregnant mice 
occurred on the morning of Day 5, when there was usually just a small area of alkaline phosphatase activity in the stroma of the antimesometrial wall, indicating a latent period of response of about $20 \mathrm{hr}$. While close histological examination of the stromal cells at this stage would probably reveal whether or not the deciduoma reaction has occurred, the demonstration of alkaline phosphatase gives clear-cut evidence of its occurrence at the earliest possible time, and would probably provide an easy and accurate end-point in bio-assays involving the reaction.

The first signs of stromal reaction were always antimesometrial. This is interesting in view of the fact that blastocysts implant on this side in the mouse, as indeed do pieces of muscle or tumour or glass beads (Blandau, 1949; Wilson, 1963). In all these cases, however, the stimulus is very localized and a decidual response can only occur in the part of the uterus to which the object is attracted, so that the interest here lies in the mechanism of attraction. Wilson suggests that blastocysts are forced into the antimesometrial area simply by muscular compression of the uterine lumen. However, in his experiments pieces of muscle or tumour, although found antimesometrially, had not caused decidual cell formation, indicating that the locating mechanism can operate without the decidual reaction. Our experiments show that a stimulus which is evenly applied over the epithelial surface sets off a decidual reaction only on the antimesometrial side. It seems therefore that two separate but successive mechanisms are involved in the initiation of the decidual cell reaction by the blastocyst. Firstly, an orientating mechanism placing the blastocyst against the antimesometrial epithelium and, secondly, a mechanism provoking decidual cell production, the latter response, however, only being possible when the blastocyst has been placed on the antimesometrial side.

The breakdown of the epithelium on the antimesometrial side which occurs on the 6th day in the oil-injected mice with the formation of a crypt, closely parallels the reaction of the pregnant uterus. It seems that once the oil has initiated the decidual response a chain of events follows spontaneously.

There has been considerable controversy about the role of the trophoblast and the spontaneous degeneration of uterine tissue in the breakdown of the epithelium during implantation (see Blandau, 1961, for a recent critical review). It is clear from the work of Blandau (1949) and Krehbiel (1937) that in the rat degeneration of the antimesometrial epithelium can take place during the decidual reaction without the presence of a blastocyst. Wilson (1963) speaks of the epithelium having, as an inherent property, "a susceptibility to degeneration and rupture". Our own work shows that an unlocalized deciduoma-producing stimulus in the mouse causes degeneration of the antimesometrial, but not of the mesometrial, epithelium. Further, sections of uterus containing implanting mouse blastocysts (our own observations) or rat blastocysts (illustrated by Blandau, 1949) show degeneration of the antimesometrial epithelium at some distance from the implanting egg. Yet, in spite of this, Blandau (1949) regards antimesometrial epithelial degeneration where a blastocyst is present as "due to the specific activities of the trophoblast giant cells". We suggest that epithelial degeneration is an inherent part of the decidual reaction whether produced by a blastocyst, or by artificial means. The fact that injection of oil 
into ovariectomized mice produces no damage to the epithelium shows that the breakdown is part of the decidual reaction rather than a direct effect of oil. Our view is nevertheless consistent with Alden's (1948) observations on the phagocytic activity of rat giant cells in engulfing surrounding epithelial cells, a phenomenon which we ourselves also observed in the implanting mouse blastocyst, and which is shown in Jenkinson's (1901-02) drawings. Presumably two mechanisms are involved in the removal of the epithelium: degeneration being followed by phagocytic activity on the part of the trophoblastic giant cells.

Much attention has been paid to the precise stimulus evoking the decidual cell reaction. One view is that put forward by Blandau (1949) that "in the rat, the evidence at hand strongly favours localized pressure as being a sufficient stimulus to induce the decidual response". Production of the decidual reaction by the traditional mechanical methods is not inconsistent with this theory. However, Wilson (1963) found that tumour or muscle tissue introduced into the pseudopregnant mouse uterus, while implanting below the epithelium and thus at some stage providing localized pressure, did not set off a decidual response. Further, Alden \& Smith (1959) demonstrated that mouse ova, fixed rat ova or fixed sea-urchin eggs (all of which would be expected to cause localized pressure on the surface of the epithelium) failed to stimulate deciduomata in the pseudopregnant rat uterus. They were able to induce deciduomata with small pieces of agar of approximately ovum size. Recently, however, Finn \& Keen (1963) have shown that a weak solution of agar (a sulphated polysaccharide) is a potent decidual stimulus, so that in Alden \& Smith's experiments their 'artificial ova' may have provided a chemical stimulus. The work reported here also tends to cast doubt on the localized-pressure theory. The volume of oil introduced is very small and by the time it reaches the oviducal end of the opposie horn, must be a very thin film over the luminal surface. Also, as shown in the earlier experiments (Finn \& Keen, 1963), many other substances which would exert a similar pressure were not effective decidual stimuli. The way in which oil initiates the reaction is still not clear. The present observations show that when oil was injected on the 4th day of pseudopregnancy, decidual development started on the following day before any change could be detected in the epithelium, indicating that the stimulus was probably not traumatic. This is further substantiated by the fact that injection of oil into the uterus of spayed mice does not injure the epithelium. In an earlier paper, Finn \& Keen (1963) showed that mineral and vegetable oils were equally effective as decidual stimuli. As mineral oils are straight-chain hydrocarbons and vegetable oils are triglycerides, it is unlikely that the chemical nature of the oil is important. Possibly some physical property associated with 'oiliness' is involved, which causes a reaction at the epithelial cell-oil boundary similar to that which occurs between the epithelium and an implanting blastocyst. Elucidation of this property might provide some indication of the nature of the stimulus provided by the blastocyst.

\section{ACKNOWLEDGMENT}

We are very grateful for the able and enthusiastic technical assistance of $\mathrm{Mr}$ Kenneth Barber. 


\section{REFERENCES}

ALDEN, R. H. (1948) Implantation of the rat egg. III. Origin and development of primary trophoblast giant cells. Amer. F. Anat. 83, 143.

Alden, R. H. \& Smith, M. J. (1959) Implantation of the rat egg. IV. Some effects of artificial ova on the rat uterus. F. exp. Zool. 142, 215.

Amoroso, E. C. (1952) Placentation. Marshall's Physiology of Reproduction, vol. 2, p. 127. Ed. A. S. Parkes. Longmans Green, London.

Blandau, R. J. (1949) Embryo-endometrial interrelationship in the rat and guinea pig. Anat. Rec. 104, 331.

Brandau, R. J. (1961) Biology of eggs and implantation. Sex and Internal Secretions, vol. 2, p. 797. Ed. W. C. Young. Baillière, Tindall \& Cox, London.

Danielli, J. F. (1953) Cytochemistry. Wiley, New York.

DE FEO, V. J. (1962) Comparative effectiveness of several methods for the production of deciduomata in the rat. Anat. Rec. 142, 226.

Finn, C. A. \& KeEn, P. M. (1962) Failure of histamine to induce deciduomata in the rat. Nature, Lond. 194, 602 .

Fins, C. A. \& KeEn, P. M. (1963) The induction of deciduomata in the rat. F. Embryol. exp. Morph. 11, 673.

Gomori, G. (1952) Microscopic histochemistry. Chicago University Press.

Jenkinson, J. W. (1901-02) Observations on the histology and physiology of the placenta of the mouse. Tijdschr. ned. dierk. Ver. 7, 124.

KREhiel, R. H. (1937) Cytological studies of the decidual reaction in the rat during early pregnancy and in the production of deciduomata. Physiol. Zoöl. 10, 212.

LOEB, L. (1908) The experimental production of the maternal placenta, and the function of the corpus luteum. F. Amer. med. Ass. 50, 1897.

Moog, F. (1944) Localization of alkaline and acid phosphatases in the early embryogenesis of the chick. Biol. Bull., Woods Hole, 86, 51.

Moog, F. \& WENGER, E. L. (1952) The occurrence of a neutral mucopolysaccharide at sites of high alkaline phosphatase activity. Amer. F. Anat. 90, 339.

Orsint, M. W. (1963) Attempted decidualization in the hamster and rat with pyrathiazine. F. Reprod. Fertil. 5, 323.

PRITchard, J. J. (1947) The distribution of alkaline phosphatase in the pregnant uterus of the rat. $\mathcal{F}$. Anat., Lond. 81, 352.

Shelesnyak, M. C. (1959) Histamine and nidation of the ovum. Mem. Soc. Endocrin. 6, 84.

Wirson, I. B. (1963) A tumour tissue analogue of the implanting mouse embryo. Proc. zool. Soc. Lond. $141,137$.

Wrenn, T. R., Bitman, J., Cecru, H. C. \& Gilliam, D. R. (1964) Uterine deciduomata: role of histamine. F. Endocrin. 28, 149. 